\title{
Statement of Methodology
}

\section{Arrangement of Materials}

The documents are printed in chronological sequence according to their dates when these are given, or according to the date of publication in cases of contemporary printed materials. Records such as diaries, journals, and account books that cover substantial periods of time appear according to the dates of their earliest entries. When no date appears on the document itself, one is editorially supplied and an explanation provided. When no day within a month is given, the document is placed at the end of all specifically dated documents of that month; those dated only by year are placed at the end of that year. If no date is given, we use internal and external evidence to assign one whenever possible, providing our explanation in annotation. Documents which cannot be assigned a date more definite than the entire length of Franklin's stay in France (I777-85) will be published at the end of this period. Those for which we are unable to provide even a tentative date will be published at the conclusion of the series.

When two or more documents have the same date, they are arranged in the following order:

I. Those by a group of which Franklin was a member (e.g., the American Commissioners in Paris)

2. Those by Franklin individually

3. Those to a group of which Franklin was a member

4. Those to Franklin individually

5. "Third-party" and unaddressed miscellaneous writings by others than Franklin.

In the first two categories letters are arranged alphabetically by the name of the addressee; in the last three, by the name of the signatory. An exception to this practice occurs when a letter to Franklin and his answer were written on the same day: in such cases the first letter precedes the reply. The same rules apply to 
documents lacking precise dates printed together at the end of any month or year.

\section{Form of Presentation}

The document and its accompanying editorial apparatus are presented in the following order:

I. Title. Essays and formal papers are headed by their titles, except in the case of pamphlets with very long titles, when a short form is substituted. Where previous editors supplied a title to a piece that had none, and this title has become familiar, we use it; otherwise we devise a suitable one.

Letters written by Franklin individually are entitled "To" the person or body addressed, as: To John Adams; To John Adams and Arthur Lee; To the Royal Society.

Letters to Franklin individually are entitled "From" the person or body who wrote them, as: From John Adams; From John Adams and Arthur Lee; From the Committee of Secret Correspondence.

Letters of which Franklin was a joint author or joint recipient are titled with the names of all concerned, as: Franklin and Silas Deane to Arthur Lee; Arthur Lee to Franklin and Silas Deane. "Third-party" letters or those by or to a body of which Franklin was a member are titled with the names of both writers and addressees, as: Arthur Lee to John Adams; The American Commissioners to John Paul Jones.

Documents not fitting into any of these categories are given brief descriptive headings, as: Extract from Franklin's Journal.

If the name in the title has been supplied from external evidence it appears in brackets, with a question mark when we are uncertain. If a letter is unsigned, or signed with initials or an alias, but is from a correspondent whose handwriting we know, the name appears without brackets.

2. Source Identification. This gives the nature of the printed or manuscript version of the document, and, in the case of a manuscript or a rare printed work, the ownership and location of the original.

Printed sources of three different classes are distinguished. First, a contemporary pamphlet, which is given its full title, 
place and date of publication, and the location of the copy the editors have used. Second, an essay or letter appearing originally in a contemporary publication, which is introduced by the words "Printed in," followed by the title, date, and inclusive page numbers, if necessary, of the publication. Third, a document, the manuscript or contemporary printed version of which is now lost, but which was printed at a later date, is identified by the words "Reprinted from," followed by the name of the work from which the editors have reproduced it. The following examples illustrate the distinction:

Printed in The Pennsylvania Gazette, October 2, 1729.

Reprinted from William Temple Franklin, ed., Memoirs of the Life and Writings of Benjamin Franklin ... (3 vols., 4to, London, I8I7-I8), II, 244.

The Source Identification of a manuscript consists of a term or symbol (all of which are listed in the Short Title List) indicating the character of the manuscript version, followed by the name of the holder of the manuscript, as: ALS: American Philosophical Society. Because press copies replicate the manuscripts from which they were made, we indicate the character of the original manuscript, as: press copy of $\mathrm{L}$. Since manuscripts belonging to individuals have a tendency to migrate, we indicate the year in which each private owner gave permission to publish, as: Morris Duane, Philadelphia, I957. When two or more manuscript versions survive, the one listed first in the Source Identification is the one from which we print.

3. An editorial Headnote precedes some documents in this edition; it appears between the Source Identification and the actual text. Such a headnote is designed to supply the background of the composition of the document, its relation to events or other writings, and any other information which may be useful to the reader and is not obtainable from the document itself.

4. The Text of the document follows the Source Identification, or Headnote, if any. When multiple copies of a document are extant, the editors observe the following order of priority in determining which of the available versions to use in printing a text: ALS or ADS, LS or DS, AL or AD, L or D, and copy. An AL (draft) normally takes precedence over a contemporary copy 
based on the recipient's copy. If we deviate from the order set forth here, we explain our decision in the annotation. In those instances where multiple texts are available, the texts are collated, and significant variations reported in the annotation. In selecting the publication text from among several copies of official French correspondence (e.g., from Vergennes or Sartine) we use the version which is written in the best French, on the presumption that the French ministers used standard eighteenthcentury spelling, grammar, and punctuation.

The form of presentation of the texts of letters is as follows:

The place and date of composition are set at the top, regardless of their location in the original manuscript.

The signature, set in capitals and small capitals, is placed at the right of the last line of the text if there is room; if not, then on the line below.

Addresses, endorsements, and notations are so labelled and printed at the end of the letter. An endorsement is, to the best of our belief, by the recipient, and a notation by someone else. When the writer of the notation has misread the date or the signature of the correspondent, we let the error stand without comment. Line breaks in addresses are marked by slashes. Different notations are separated by slashes; when they are by different individuals, we so indicate.

5. Footnotes to the Heading, Source Identification, Headnote, and Text appear on the pages to which they pertain. References to documents not printed or to be printed in later volumes are by date and repository, as: Jan. 17, 1785, APS.

\section{Method of Textual Reproduction}

I. Spelling of all words, including proper names, is retained. If it is abnormal enough to obscure the meaning we follow the word immediately with the current spelling in brackets.

2. Capitalization and Punctuation are retained. There is such variety in the size of initial letters, often in the same manuscript, that it is sometimes unclear whether the writer intended an upper or lower case letter. In such cases we make a decision on the basis of the correspondent's customary usage. We supply a capital letter when an immediately preceding period, colon, question mark, exclamation point, or dash indicates that a new 
sentence is intended. If a capital letter clearly indicates the beginning of a new thought, but no mark of punctuation precedes it, we insert a period. If neither punctuation nor capital letter indicates a sentence break, we do not supply them unless their absence renders comprehension of the document nearly impossible. In that case we provide them and so indicate in a footnote.

Dashes were used for a variety of purposes in eighteenthcentury personal and public letters. A dash within a sentence, used to indicate a break in thought, is represented as an em dash. A dash that follows a period or serves as a closing mark of punctuation for a sentence is represented as an em dash followed by a space. Occasionally correspondents used long dashes that continue to the end of a line and indicate a significant break in thought. We do not reproduce the dash, but treat it as indicating the start of a new paragraph.

When there is an initial quotation mark or parenthesis, but no closing one, we silently complete the pair.

3. Contractions and abbreviations are retained. Abbreviations such as "wd", "honble", "servt", "exclly", are used so frequently in Franklin's correspondence that they are readily comprehensible to the users of these volumes. Abbreviations, particularly of French words, that may be unclear are followed by an expanded version in brackets, as: nre [navire]. Superscript letters are brought down to the line. Where a period or colon is a part of the abbreviation, or indicates that letters were written above the line, we print it at the end of the word, as: 4 th. for $4 \cdot^{\text {th }}$. In those few cases where superscript letters brought down to the line result in a confusing abbreviation ("Made" for "Mad"), we follow the abbreviation by an expanded version in brackets, as: Made [Madame].

The ampersand by itself and the "\&c." are retained. Letters represented by the "y" are printed, as: "the" and "that". The tailed "p" is spelled out, as: "per", "pre", or "pro". Symbols of weights, measures, and money are converted to modern forms, as: l.t. instead of $\mathbb{H}$ for livres tournois.

4. Omissions, mutilations, and illegible words are treated as follows:

If we are certain of the reading of letters missing in a word 
because of a torn or taped manuscript or tightly bound copybook, we supply the letters silently.

If we cannot be sure of the word, or of how the author spelled it, but we can make a reasonable guess, we supply the missing letters in brackets.

When the writer has omitted a word absolutely required for clarity, we insert it in italics within brackets.

5. Interlineations by the author are silently incorporated into the text. If they are significant enough to require comment a footnote is provided.

Textual Conventions

/

$\langle$ roman〉

[italic]

[roman] denotes line break in addresses; separates multiple endorsements and notations.

denotes a résumé of a letter or document.

editorial insertion explaining something about the manuscript, as: [one line illegible]; or supplying a word to make the meaning clear, as: $[t o]$.

editorial insertion clarifying the immediately preceding word or abbreviation; supplies letters missing because of a mutilated manuscript. indicates a questionable reading. 